\title{
A FLEXIBILIZAÇÃO DA LEGISLAÇÃO TRABALHISTA BRASILEIRA: A REDUÇÃO DOS DIREITOS GARANTIDOS PELA CONSOLIDAÇÃO DAS LEIS DO TRABALHO AO LONGO DO TEMPO
}

Alisson Droppa*

\section{RESUMO:}

As relações de trabalho no Brasil são regulamentadas pela Consolidação das Leis do Trabalho, CLT, sancionada pelo Decreto-Lei n5452 de maio de 1943, que, desde então, passou a sofrer constantes ataques dos setores patronais. Durante o período da ditatura civil militar no Brasil, que se iniciou com o golpe de $1^{\circ}$ de abril de 1964 , foi aprovado um conjuntos de leis que atribuíram nova redação a dispositivos da CLT, correspondendo ao que alguns convencionaram chamar de "primeira onda liberal", tais como: a lei que criou o Fundo de Garantia por Tempo de Serviço, FGTS, e acabou com o instituto da estabilidade no emprego, com vigência a partir de janeiro de 1967; a lei de greve, de 1964. O presente artigo busca estabelecer um diálogo entre esses ataques às leis sociais, a primeira onda liberal, com as tentativas mais recentes, em curso no Brasil, no sentido de novo ataque aos direitos sociais. Palavras-chave: Legislação social; Direito do Trabalho; Flexibilização.

\section{ABSTRACT:}

The working relations in Brazil are regulated by the Consolidação das Leis do Trabalho, CLT, sanctioned by the Decree $\mathrm{n}^{\circ} 5452$ from May 1943, that ever since, was constantly fought against by employers. During the civil-military dictatorship in Brazil, initiated with the coup of 1 April 1964, it was approved a set of laws that enacted new texts to CLT legal devices. That corresponded to what some have called "first liberal wave", with measures such as the law that created the Fundo de Garantia por Tempo de Serviço, FGTS, and ended up with the institution of employment stability, enacted in January 1967 and the strike law, enacted in 1964. The following paper intends to establish a dialogue between those attacks against social laws, the "first liberal wave" and the most recent attacks happening against the social right in Brazil nowadays.

Keywords: Social legislation; Labor Law; Flexibilization.

As relações de trabalho no Brasil são regulamentadas pela Consolidação das Leis do Trabalho, CLT, sancionada pelo Decreto-Lei nº5452 de maio de 1943, que, desde então, passou a sofrer constantes ataques dos setores patronais. Durante o período da ditatura civil militar no Brasil, que se iniciou com o golpe de $1^{\circ}$ de abril de 1964 , foi aprovado um

\footnotetext{
* Doutor em História Social pela Universidade Estadual de Campinas/ UNICAMP (2015). Mestre em História pela Universidade do Vale do Rio dos Sinos (2009). Licenciado em História pela Universidade Regional do Noroeste do Estado do Rio Grande do Sul (2005).
} 
conjuntos de leis que atribuíram nova redação a dispositivos da CLT, correspondendo ao que alguns convencionaram chamar de "primeira onda liberal", tais como: a lei que criou o Fundo de Garantia por Tempo de Serviço, FGTS, e acabou com o instituto da estabilidade no emprego, com vigência a partir de janeiro de 1967; a lei de greve, de 1964. O presente artigo busca estabelecer um diálogo entre esses ataques às leis sociais, a primeira onda liberal, com as tentativas mais recentes, em curso no Brasil, no sentido de novo ataque aos direitos sociais.

No dia 10 de novembro de 2016 comemorou-se o 73 aniversário da Consolidação das Leis do Trabalho, CLT, aprovada pelo Decreto-Lei $n^{\circ} 5.432$, de $1^{\circ}$ de maio de 1943 , assinado pelo Presidente Getúlio Vargas e pelo Ministro do Trabalho, Indústria e Comércio, Alexandre Marcondes Filho, para viger em 10 de novembro daquele ano. A história de sua construção está profundamente imbricada ao processo de industrialização e modernização do Brasil e às iniciativas do governo de constituir um arcabouço jurídico que incluiu a legislação social do trabalho e a criação da Justiça do Trabalho e do sistema de fiscalização do cumprimento dessa nova tela de proteção social, ainda em construção. Além da própria luta dos trabalhadores brasileiros por melhores condições de trabalho.

Seus últimos aniversários têm sido marcados por forte polêmica teórica. De um lado, setores empresariais, economistas e estudiosos, adeptos a certa corrente de pensamento, destacam a incompatibilidade de sua "rigidez" com os "tempos modernos", defendendo que, para o incremento da produtividade a da competitividade em nível mundial, deve ela ser flexibilizada. A ideia é a de que a CLT permaneceu estanque às transformações econômicas, como exemplifica reportagem da Revista Exame, de $1^{\text {o }}$ de maio de 2013, em "comemoração" aos seus 70 anos. Depois de entrevistar estudiosos e um trabalhador, a jornalista concluiu faltar "sintonia" entre a realidade do mundo do trabalho brasileiro e a legislação. Para fortalecer seu argumento, invocou André Portela, professor da Escola de Economia da Fundação Getúlio Vargas, São Paulo, instituição conhecida por seu viés liberal: “A CLT precisa passar o bastão para outra legislação”, eis que, ainda que tenha sido importante para os primórdios do capitalismo brasileiro, "não cabe mais no século 21 " 1 .

De outro lado, expoentes do pensamento econômico heterodoxo afirmam ser equivocado atribuir à regulamentação do trabalho o motor da competitividade, defendendo que os direitos sociais, conquistados contra as "leis naturais" do capitalismo, não podem sucumbir frente à competição internacional dos mercados. Isso em tempos em que nos quatro

\footnotetext{
${ }^{1}$ SALOMÃO, Alexa. Está difícil conviver com a CLT. Revista Exame. http://exame.abril.com.br/revistaexame/edicoes/1040/noticias/nem-ele-entende-mais-a-clt. Acesso em 20 de set.2016.
} 
cantos do mundo, salvo exceções, os direitos sociais perdem terreno à ação da "força bruta" de um capitalismo "sem peias". 2 .

Este artigo dialoga com esses argumentos, partindo do pressuposto de que a legislação trabalhista é flexível, com alterações pontuais que foram sendo realizadas em resposta às fortes pressões no sentido da desconstrução das conquistas dos trabalhadores. A historiografia brasileira tem apontado que o golpe civil-militar de 1964, que destituiu o presidente João Goulart quando em discussão importantes reformas de base, interrompeu o "processo de ascensão da mobilização da classe trabalhadora brasileira", ${ }^{3}$ momento em que: "Uma política econômica antitrabalhista proibiu greves, comprimiu salários, acabou com a estabilidade no emprego, facilitando demissões e a rotatividade da mão de obra"4. Durante os governos militares, uma "primeira onda liberal" impactou as relações de trabalho, busca-se, neste texto, proceder a um diálogo entre essa “onda", que se contrapôs a alguns princípios fundantes do Direito do Trabalho e aquela posterior, iniciada na década de 1990, que buscou desconstruiu a tela de proteção social, com ênfase à terceirização.

O artigo está assim estruturado: inicia com rápida contextualização do período brasileiro em que a CLT foi elaborada. Depois, olhando para seu processo de elaboração, destaca algumas leis e assinala a importância das normas de proteção social para a constituição de uma sociedade mais integrada e de instituições públicas aptas a fiscalizar sua aplicação e a concretizá-las. Seguem abordagens sobre o processo de desconstrução dessa tela de proteção social, incluída a primeira "onda liberal” - período da ditadura civil-militar - bem como a segunda - especialmente, década de 1990 -, buscando proceder a um diálogo entre elas. Por último, as considerações finais.

\section{A CLT e o momento de sua construção}

As considerações a seguir estão fundamentadas em tese apresentada por uma das autoras deste artigo, Magda Barros Biavaschi, ao Instituto de Economia da Unicamp, para

2 Ver BELLUZZO, Luiz Gonzaga. O capital e suas metamorfoses. São Paulo: UNESP, 2013. Ver, também: KREIN, José Dari; BIAVASCHI, Magda Barros. Brasil: os movimentos contraditórios da regulação do trabalho dos anos 2000. CDC [online]. 2015, vol.32, n.89, pp. 47-82.

3 NEGRO, Antonio Luigi; CORRÊA, Larissa Rosa; FONTES, Paulo. Trabalhadores e Ditadura. Mundos do Trabalho, Florianópolis, v. 6, n. 11, p. 5-8, jan. 2015. ISSN 1984-9222. Disponível em: <https://periodicos.ufsc.br/index.php/mundosdotrabalho/article/view/1984-9222.2014v6n11p5/28614>. Acesso em: 13 set. 2016. doi:http://dx.doi.org/10.5007/1984-9222.2014v6n11p5.

${ }^{4}$ Ibidem.

5 Ver a tipologia "primeira" e "segunda onda liberal", desenvolvida por Marcio Pochmann: POCHMANN, Marcio. A segunda onda liberal sobre o trabalho no Brasil. Folha de São Paulo, 25 jan.1998 (Caderno Mercado), disponível em: http://www1.folha.uol.com.br/fsp/dinheiro/fi250104.htm. Acesso: 03 out.2016. 
obtenção do título de doutora em Economia Social do Trabalho, publicada em $2007^{6}$ que, como uma das questões centrais, demonstrou que a tese da cópia fascista atribuída à legislação trabalhista brasileira não se sustenta teórica e empiricamente. Também têm como referência artigo da mesma autora, A construção das normas de proteção social ao trabalho e seus fundamentos, ${ }^{7}$ publicado em livro em homenagem à Professora Gabriela Neves Delgado

Para se compreender o Direito do Trabalho a partir de seus fundamentos, a lente utilizada é de longa duração. O olhar, assim, desloca-se para o Século XIX, em tempos de capitalismo constituído e de laissez faire, focando a Grande Indústria Inglesa em que a venda assalariada da força de trabalho, de forma não eventual e subordinada, se dava de forma prevalente. Estavam dadas as condições para o nascimento de um novo ramo do Direito, que viria mais tarde, fundamentado em princípios forjados no campo das lutas sociais. "Direito esse que nasceu em um cenário em que a natureza do Estado foi sendo modificada e a Ordem Liberal solapada. E em que, ao invés da prometida sociedade de homens iguais, livres e fraternos, o novo modo de produção acirrava desigualdades e aprofundava iniquidades" 8 .

De um lado, trabalhadores e trabalhadoras, adultos e crianças, sem qualquer proteção social. Coisas vendidas como mercadorias. De outro, os compradores da força de trabalho, detentores dos bens de produção que, movidos por um desejo insaciável de acumulação da riqueza abstrata e com a força bruta do capital, buscavam eliminar todos os obstáculos a esse "livre trânsito". No entanto, concentrados ao redor das máquinas, nas fábricas, os trabalhadores agregavam-se, sucedendo-se lutas, uma mais organizada do que a outra, com o objetivo de verem reduzidas as jornadas, aumentados os salários e melhoradas as condições de trabalho. ${ }^{9}$ Estruturavam-se movimentos de resistência. Os trabalhadores e suas organizações pressionavam pela positivação de normas de proteção que reduzissem as injustiças e as desigualdades acirradas pelo novo modo de produção, o capitalista.

O Estado liberal clássico do laissez-faire, colocado em xeque, passou a intervir nas relações sociais produzindo normas. Aqui se localiza a gênese do Direito do Trabalho. Isto é, o momento da história em que as condições materiais, políticas, sociais, possibilitaram a

\footnotetext{
${ }^{6}$ BIAVASCHI, Magda Barros. O Direito do Trabalho no Brasil - 1930-1942: a construção do sujeito de direitos trabalhistas. São Paulo: LTr, 2007.

${ }^{7}$ BIAVASCHI, Magda Barros. A construção das normas de proteção social ao trabalho e seus fundamentos: uma homenagem à Professora Gabriela Neves Delgado. In: VIANA, Márcio Túlio: ROCHA, Cláudio Jannotti da (Orgs.). Como aplicar a CLT à luz da Constituição: alternativas para os que militam no foro trabalhista. São Paulo: LTr, 2016, p. 19-27.

${ }^{8}$ BIAVASCHI, Magda Barros. Exposição de Motivos. In: A CLT comentada/Rodrigo Trindade de Souza, Coordenador. São Paulo: LTR, 2015, p. 22.

${ }^{9}$ Belluzzo, como se trata de relação de poder, há lugar para a política e para ação. BELLUZZO, Luiz Gonzaga. Valor e Capitalismo. Brasiliense: São Paulo, 1980.
} 
emergência ulterior de um novo ramo do Direito que, forjado no campo das lutas sociais, “... desde sua gênese, rompeu com a lógica liberal da igualdade das partes e, informado por princípios próprios, tendo como objeto o trabalho humano, "livre", por conta alheia, não eventual, subordinado e remunerado, buscava compensar a assimetria nas relações de poder na indústria, colocando diques à ação trituradora do capital" ${ }^{10}$, tendo na dignidade humana o ponto de partida. ${ }^{11}$

Esses princípios são construções históricas que the dão fisionomia e são seus fundamentos. Porém, ainda que sua gênese se localize no século XIX, até a Primeira Guerra Mundial, 1914-1918, grosso modo, não se lhe reconheceu o caráter de ramo autônomo do Direito. A Organização Internacional do Trabalho, que veio com o pacto de Versalhes, em 1919, foi marco decisivo nesse processo. Nessa caminhada, chega-se ao Brasil de 1930 e às suas especificidades. Um Brasil que, à época, era essencialmente agrário, com grande parte da população vivendo e trabalhando na zona rural. ${ }^{12} \mathrm{O}$ gráfico 01 , que segue, é esclarecedor. Durante a década de 1920, o produto agrícola brasileiro representou, em média, 58\% do PIB, enquanto a indústria 23\%. Foi entre 1941-1947 que a indústria começou a superar a agricultura.

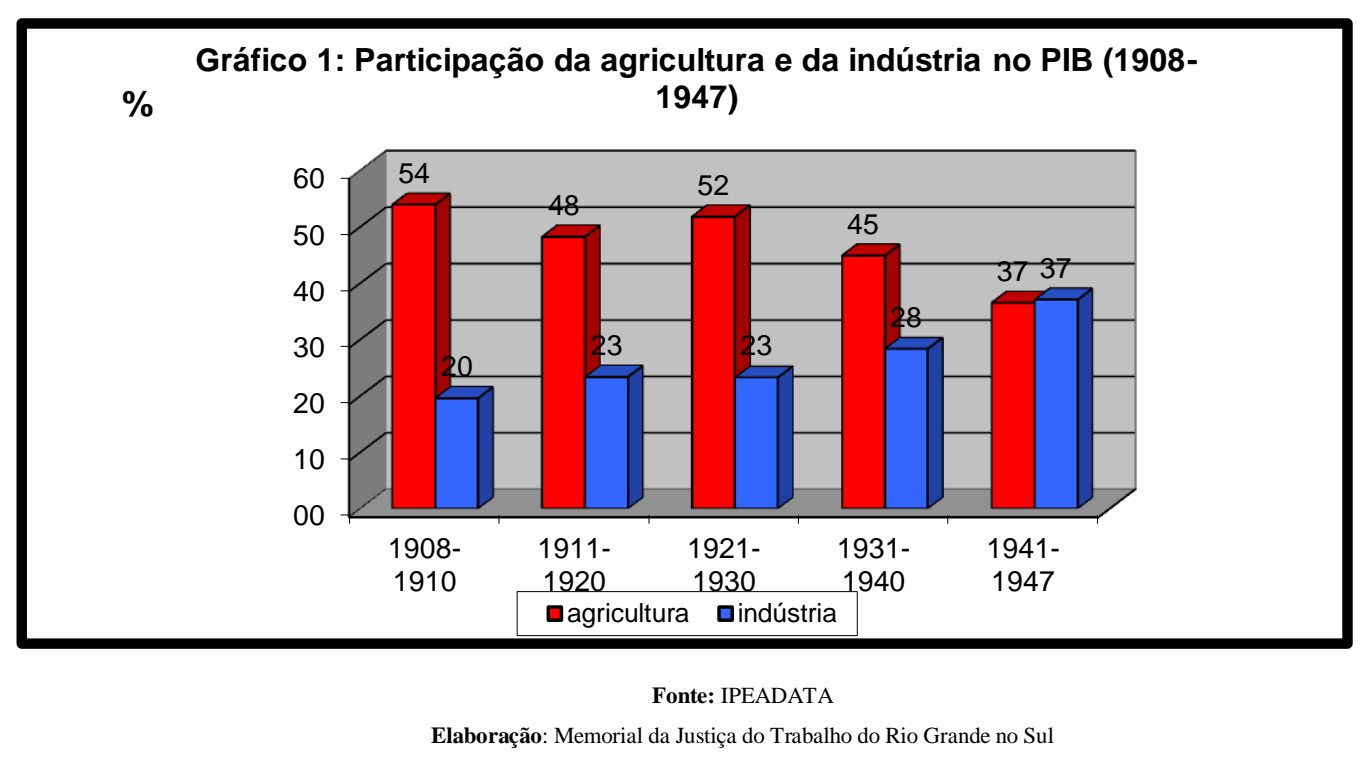

Em 1930, derrotada da Aliança Liberal nas urnas - o gaúcho Getúlio Vargas era candidato à Presidência e o paraibano João Pessoa à Vice -, reuniram-se homens de grande talento político em torno do triunfante movimento revolucionário que, em outubro de 1930, assumiram o poder sob a batuta de Vargas. O Governo Provisório iniciava-se em meio a uma

\footnotetext{
${ }^{10}$ BIAVASCHI, Magda Barros. A construção das normas de proteção social ao trabalho e seus fundamentos: uma homenagem à Professora Doutora Gabriela Neves Delgado, op cit, p. 21.

${ }^{11}$ Ibidem.

12 BIAVASCHI, Magda Barros. O Direito do Trabalho no Brasil - 1930-132, op cit.
} 
profunda crise econômica.

Para cumprir as promessas da Aliança Liberal de industrializar o país e transformá-lo em uma nação moderna, ainda que as questões internas devessem ser equacionadas, o Brasil não se descolou do contexto internacional, dialogando com as experiências de intervenção do Estado nas relações econômicas e sociais: a russa, com a Revolução de 1917; o pioneirismo da socialdemocracia Sueca; a experiência fascista da Itália; o New Deal dos EUA; o nazismo da Alemanha. A humanidade respondia à crise de forma antiliberal, seja democraticamente, seja pela via autoritária.

Sem deixar de dialogar com essas realidades, Vargas voltou-se às grandes questões internas $^{13}$ visando a adotar medidas que amenizassem os efeitos da crise e levassem o país a superar suas dependências e vulnerabilidades ${ }^{14}$. Essa caminhada envolvia expansão econômica fundada em novas bases, numa dinâmica específica e própria do processo de constituição das condições materiais do capitalismo, formação de suas classes (basicamente a burguesia industrial e o proletariado) e construção dos aparelhos de Estado. O Brasil passou a lutar pela superação dos resquícios da ordem patriarcal, monocultora e escravocrata herdada dos tempos coloniais. O tema do Direito do Trabalho insere-se nessa complexidade.

Esse período foi marcado pela consolidação na produção de normas de proteção ao trabalho, como, entre outras: a Lei dos Dois Terços ${ }^{15}$; a carteira de trabalho ${ }^{16}$; a fixação da jornada para trabalhadores do comércio e da indústria, sem distinção de sexo $^{17}$; o sufrágio universal e o voto feminino ${ }^{18}$; os direitos das mulheres e dos menores ${ }^{19}$; a extensão da estabilidade no emprego assegurada aos ferroviários em $1923^{20}$; o salário mínimo. Esse processo normativo passou pela criação das Inspetorias Regionais ${ }^{21}$, das Juntas de Conciliação e Julgamento, paritárias, embrião da Justiça do Trabalho ${ }^{22}$ criada em 1939 e instalada em 1941

\footnotetext{
${ }^{13}$ FONSECA, Pedro Cezar Dutra. Vargas: o capitalismo em construção - 1906-1954. São Paulo: Brasiliense, 1989.

${ }^{14}$ Idem, p. 150-160.

${ }^{15}$ Decreto 19.482 , de 12.12 .1930$.

${ }^{16}$ Decreto 21. 175, de 21.03.1932.

${ }^{17}$ Decreto 21.186, de 22 de março de 1932, seguido de outros, para o comércio; Decreto 21.364, de 4 de maio de 1932, seguido de outros, para a indústria.

${ }_{18}$ Decreto $21.076,24.02 .1932,4^{\circ}$ país do hemisfério ocidental a assegurá-lo.

19 Decreto 21.417-A, de 17 de maio de 1932 regulou as condições de trabalho da mulher na indústria e n o comércio, atribuindo-lhe salário igual a trabalho de igual valor, sem distinção de sexo. Também proibiu o trabalho da gestante nas 04 semanas antes e depois do parto. O artigo 13 trouxe regra não incorporada pela CLT: proibia a despedida das grávidas pelo fato da gravidez.

${ }^{20}$ Lei $\mathrm{n}^{\circ} 62 / 35$, de 5 de junho de 1935 .

${ }^{21}$ Decreto 21.690, de 1ㅇ de agosto de 1932, criou as Inspetorias Regionais nos Estados e Território do Acre, embrião das Delegacias Regionais do Trabalho. Outros se seguiram.

${ }^{22}$ Decreto-lei 1.237 , de 02 de maio de 1939 e o Decreto-lei 2.851 , de 10 de dezembro de 1940, organizaram a Justiça do Trabalho. O Decreto-lei 1.346, de 15 de junho de 1939, reorganizou o Conselho Nacional do
} 
e pela CLT, culminando na Constituição 1988 que elevou os direitos dos trabalhadores à condição de direitos sociais fundamentais. Nessa démarche, tanto a Justiça do Trabalho como a CLT sofreram oposição ferrenha dos setores mais conservadores da sociedade, ameaçadas aqui e ali. Afinal, pedras no sapato dos que querem eliminar os obstáculos ao livre trânsito de um capitalismo "sem peias".

O estabelecimento da CLT e a introdução de novas leis sociais no arcabouço jurídico brasileiro e mesmo a consolidação do Direito do Trabalho, na década de 1940, como novo ramo do Direito não pode quer dizer necessariamente que a legislação passou a ser aplicada e reconhecida de forma automática. A aplicação da legislação social necessitou ser estruturada: implantação de Tribunais do Trabalho nas diversas regiões brasileiras, JCJ, além da necessidade real dos trabalhadores conhecerem seus direitos e reivindicarem sua aplicação.

Os gráficos abaixo ilustram a afirmativa de uma evolução gradual no número de JCJ ao longo dos anos e o consequente aumento no número de reclamatórias que podem indicar a efetivação do sistema implantado na década de 1940. Os números também fortalecem a hipótese que os trabalhadores fizeram tomaram a arena judicial como um espaço de luta por direitos.

Gráfico 1 - JCJs em funcionamento no TRT4 1941 a 1965

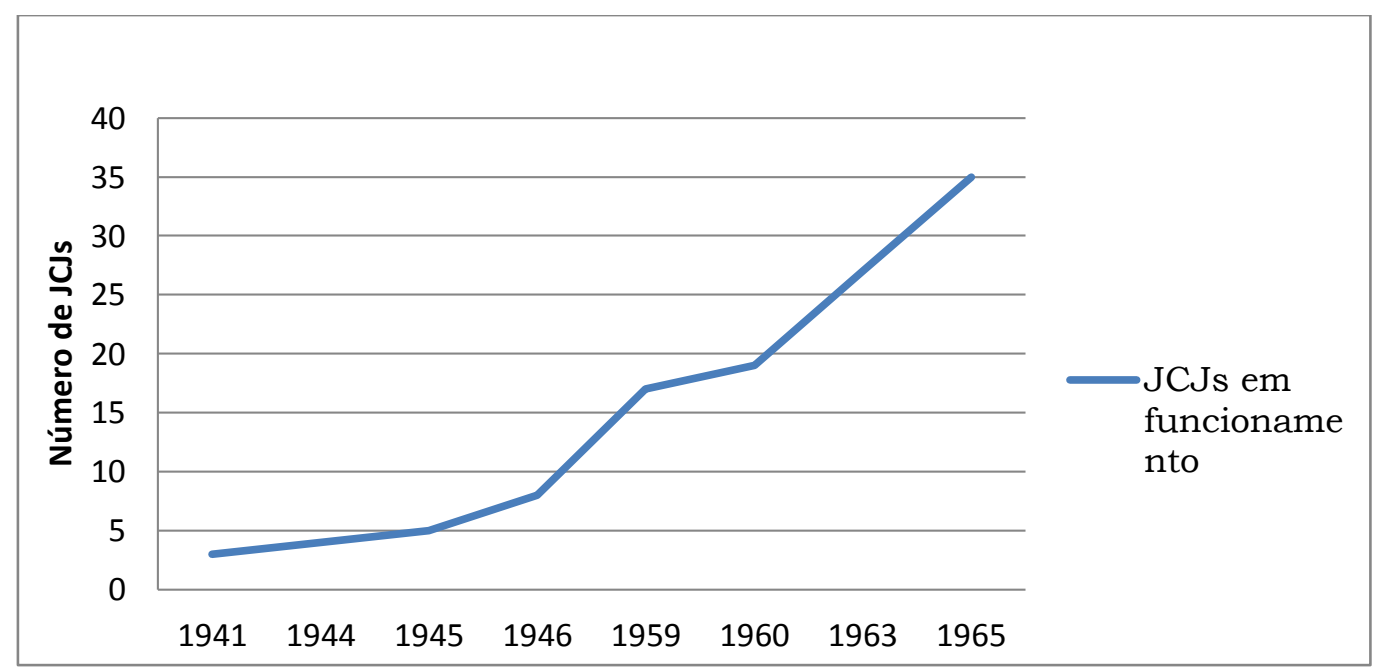

Fonte: Memorial da Justiça do Trabalho no Rio Grande do Sul 
Gráfico 2 - Total de reclamatórias encaminhadas às JCJ de Porto Alegre no Período 1941 a 1964.

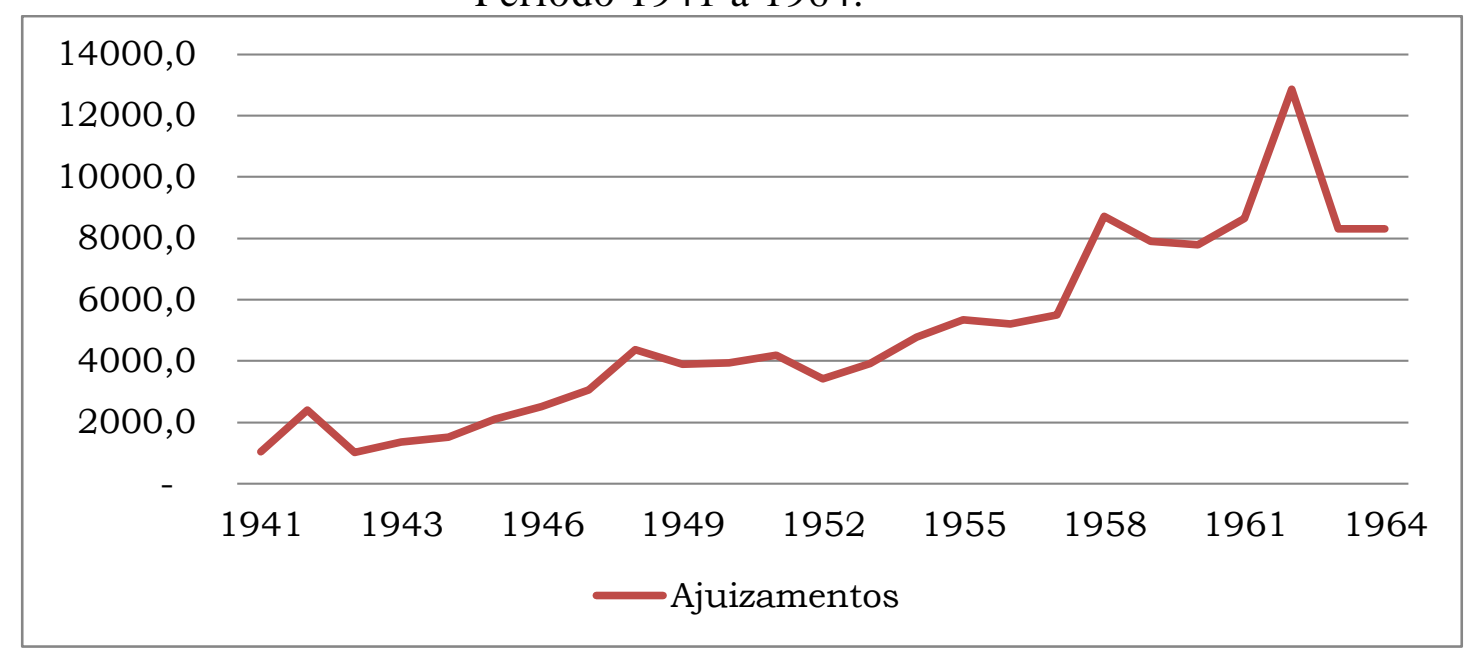

Fonte: Memorial da Justiça do Trabalho no Rio Grande do Sul

Para este artigo é importante salientar que a CLT representou um avanço no sentido de garantir direitos que representaram um patamar civilizatório, colocando diques à ação de um capitalismo em processo de constituição, com positivação de regras que foram incorporando princípios que dão fisionomia ao Direito do Trabalho, sendo sua razão de ser. Entre outros princípios estão: o da proteção, o da aplicação da norma mais favorável, o da aplicação da regra da condição mais benéfica, o da irrenunciabilidade dos direitos assegurados por normas de ordem pública, o da irredutibilidade salarial, o da primazia da realidade. Seus artigos $9^{\circ}, 444$ e 468, por exemplo, reproduzem teses apresentadas por Arnaldo Süssekind, um dos membros da comissão que redigiu a CLT, no $1^{\circ}$ Congresso de Direito Social, em 1941, cuja preocupação era a de coibir a fraude aos direitos que estavam sendo inscritos no ordenamento jurídico.

Art. $9^{\circ}$ - Serão nulos de pleno direito os atos praticados com o objetivo de desvirtuar, impedir ou fraudar a aplicação dos preceitos contidos na presente Consolidação.

(...)

Art. 444 - As relações contratuais de trabalho podem ser objeto de livre estipulação das partes interessadas em tudo quanto não contravenha às disposições de proteção ao trabalho, aos contratos coletivos que lhes sejam aplicáveis e às decisões das autoridades competentes.

(...)

Art. 468 - Nos contratos individuais de trabalho só é lícita a alteração das respectivas condições por mútuo consentimento, e ainda assim desde que não resultem, direta ou indiretamente, prejuízos ao empregado, sob pena de nulidade da cláusula infringente desta garantia.

Parágrafo único - Não se considera alteração unilateral a determinação do empregador para que o respectivo empregado reverta ao cargo efetivo, anteriormente ocupado, deixando o exercício de função de confiança. ${ }^{23}$

\footnotetext{
${ }^{23}$ https://www.planalto.gov.br/ccivil_03/Decreto-Lei/Del5452.htm
} 
Outro exemplo, o artigo $2^{\circ}$, caput, e seu $\S 2^{\circ}$, tratando da figura do empregador e da responsabilidade solidária das empresas que compõem um mesmo grupo econômico. No caput, define: empregador é quem, assumindo os riscos da atividade econômica, dirige a prestação dos serviços contratados, de forma direta, sem prever a figura de um terceiro atravessando o binômio empregado e empregador. Já o parágrafo define a responsabilidade solidária no caso de grupo econômico, garantindo ao empregado o direito de receber a integralidade de seu crédito de qualquer uma das empresas que participem do conglomerado. Difere da responsabilidade subsidiária porquanto nesta responde pelos créditos a contratante e, apenas na impossibilidade desta pagar, a cobrança será dirigida à responsável subsidiária. O princípio da continuidade da relação de emprego, que fundamenta o instituto da estabilidade, presente no artigo 492 da CLT, recebeu um golpe na primeira “onda liberal”, como se verá. Já os princípios da intangibilidade e da irredutibilidade salarial, que partem do pressuposto de que salário é alimento, assegurada sua integralidade e impenhorabilidade, foram desrespeitados na "segunda onda liberal" por normas que não os incorporaram.

\section{A CLT e a "primeira onda liberal"}

Os princípios, construções históricas como se viu, são incorporados pelas normas postas pelo Estado. De tal sorte que não há normas sem princípios. Pode haver princípios ainda não contemplados pelas normas vigentes. Por outro lado, o capitalismo é muito criativo, engendrando sempre novas formas de organização e contratação visando a saciar o seu desejo insaciável de acumulação de riqueza, em verdadeira compulsão. ${ }^{24}$ No curso do movimento do capitalismo as bases da legislação social foram sempre muito atacadas, porquanto pedras ao seu "livre trânsito". No período da ditadura civil militar brasileira, conforme Pochmann, uma "primeira onda liberal" correspondeu a uma tentativa conservadora de rompimento no processo de evolução da regulação social do trabalho, sendo flexibilizados certos aspectos da CLT e desrespeitados princípios estruturantes, como: a lei de greve, de $1^{\circ}$ de junho de 1964, Lei $n^{\circ}$ 4.330, que disciplinou as greves, fragilizando a organização dos trabalhadores; o ataque à estabilidade no emprego, conquista dos ferroviários em 1923, com a Lei Eloy Chaves, estendida aos trabalhadores da indústria e do comércio pela Lei 62, de 1935, incorporada à CLT de 1943, sendo ferido o princípio da continuidade da relação de emprego, próprio do Direito do Trabalho; o esvaziamento do Poder Normativo da Justiça do Trabalho em face do disposto na Lei $\mathrm{n}^{\mathrm{o}} 4.725 / 65$, que buscou controlar os salários vedando sub correção pelos

\footnotetext{
${ }^{24}$ SCHUMPETER, Joseph A. Capitalismo, socialismo e democracia. New York: Harper \& Row, 1975.
} 
índices inflacionários; a Lei $\mathrm{n}^{\circ}$ 6019/74 que, legitimando a contratação de trabalho temporário via relação "trilateral" ou assimétrica, introduziu a figura do terceiro atravessando o binômio empregado e empregador.

\section{O direito de greve e a lei de greve de 1964}

O jogo de forças estabelecido nos tribunais entre patrões e empregados, em tese com suas regras prefinidas em uma legislação em formação, era exercido até 1964 por meio dos dissídios coletivos que analisavam a legalidade ou não dos movimentos paredistas. Por um lado, o exercício de greve no âmbito dos dissídios coletivos sofria os limites impostos pelos julgadores e pelas restrições do Decreto-lei n 9070 , de março de 1946, que burocratizava, limitava e restringia as possibilidades do movimento grevista ser considerado "legal” pela Justiça do Trabalho. Por outro, tinha fundamentação na Constituição de 1946, que o garantia como um direito.

O artigo 158 da Constituição Federal de 1946 reconhecera o direito de greve, remetendo à lei a regulamentação do seu exercício. Visando a essa regulamentação, foi encaminhado projeto de lei que, em 1949 tramitava na Câmara dos Deputados sob $n^{\circ}$ 1471. Sua tramitação foi muito lenta, sendo, em $1^{\circ}$ de junho de 1964 , retornando do Senado, transformado na Lei $\mathrm{n}^{\circ}$ 4330/64, encaminhado à sanção presidencial. Na ausência de lei regulamento o direito constitucional, vigeu o anterior Decreto Lei $n^{\circ}$ 9.070, de 1946, conforme, inclusive, entendimento consagrado pelo Supremo Tribunal Federal. Na prática era a legislação sobre o exercício da greve. Seu conteúdo amplo, não limitado, apenas, a regulamentar o direito de greve mas, também, os conflitos coletivos não solucionados via negociação, permitiu que os organizações dos trabalhadores fizessem uso dessa normatização como ferramenta para reivindicar direitos. ${ }^{25}$ No bojo da "primeira onda liberal", é aprovada a referida Lei 4330, chamada pelos trabalhadores como a "lei antigreve", que limitou o exercício da greve a diversas condicionantes que, na realidade, criavam reais obstáculos à concretização desse direito. As greves de solidariedade e as consideradas de natureza política, social, ou religiosa, eram consideradas ilegais. As exigências burocráticas que a lei impunha dificultavam as greves, como referiu

\footnotetext{
${ }^{25}$ DROPPA, Alisson. Direitos Trabalhistas: Legislação, Justiça do Trabalho e Trabalhadores no Rio Grande do Sul (1958- 1964). Tese de doutorado em História. UNICAMP/IFCH, Campinas, 2015.
} 
Larissa Rosa Corrêa ${ }^{26}$. Nesse sentido, a nova lei atingiu drasticamente a luta dos trabalhadores por direitos.

\section{O Fundo de Garantia por Tempo de Serviço}

O Artigo 492 da CLT garantia expressamente aos trabalhadores com mais de 10 anos de serviço na mesma empresa o direito ao emprego, não podendo ser despedido sem "falta grave ou circunstância de força maior” comprovadas em inquérito específico. Trata-se de direito incorporado pela Lei $\mathrm{n}^{\circ}$ 62/35 que estendeu a estabilidade decenal dos ferroviários aos empregados da indústria e do comércio. A CLT incorporou esse direito no artigo citado, fundamentado no princípio da continuidade da relação de emprego. Muitos os trabalhadores e trabalhadoras despedidos sem o cumprimento das exigências da CLT foram reintegrados, declarado nulo o ato de despedimento pela Justiça do Trabalho. Esse princípio, que fisionomiza o Direito do Trabalho, foi violentado com a aprovação da Lei $n^{\circ}$ 5107, de 13 de setembro de 1966, que trouxe para o ordenamento jurídico trabalhista o direito potestativo de o empregador despedir, ou seja, a denúncia vazia do contrato, sem exigir qualquer motivação para o ato. Como compensação, a lei instituiu o Fundo de Garantia do Tempo de Serviço, o FGTS, podendo ser sacado pelo trabalhador nas hipóteses por ela previstas. Dessa forma, foi escancarada a porta de saída da relação de emprego, ampliando-se a rotatividade de mão-deobra no Brasil. Essa lei foi marco liberalizador do mercado de trabalho brasileiro, sendo seguida de outras, que serão focadas.

\section{A Lei 4.725/1965 e a correção dos salários pela inflação}

Segundo Larissa Correa ${ }^{27}$, desde a criação da Justiça do Trabalho até o golpe civil militar, a tendência decisória dos Tribunais Trabalhistas era a de concederem reajustes salariais tomando como base a média entre a solicitação dos trabalhadores, a oferta dos patrões e os índices oficiais de inflação. Segundo ela, a partir de 1964 o Executivo passou a pré-fixar índices de reajustes, visando ao achatamento dos salários.

Em entrevista publicada no jornal O Estado de São Paulo, 31 de agosto de 1965, o então Ministro da Fazenda, Octávio Gouvêa Bulhões, pediu colaboração aos Tribunais do Trabalho para a concretização de novo plano econômico. Nas palavras do Ministro, a conjuntura demandava sacrifício dos trabalhadores e ponderação dos juízes, já que o

\footnotetext{
${ }^{26}$ CORREA, Larissa Rosa. Os inimigos da pátria: repressão e luta dos trabalhadores do sindicato dos químicos de São Paulo (1964-1979), Revista Brasileira de História. São Paulo, V. 34, nº 67, p.13-37, 2014.

${ }_{27}$ Corrêa, Larissa Rosa. A rebelião dos índices: política salaria e Justiça do Trabalho na ditadura Civil-Militar (1964-1968).
} 
governo estava impondo apreciável transferência de poder de compra dos consumidores para agricultores e pecuaristas. Os sindicatos deveriam demandar apenas ajustes módicos no salário, esperando que os Tribunais não insistissem em invalidar tão fundamental política de reciprocidade sob fundamentos outros que não os essenciais ao desenvolvimento econômico do país. $^{28}$

Como esse pedido de "colaboração" não funcionou, a solução encontrada pelo regime ditatorial foi a Lei no 4725/1965, conhecida como Lei do Arrocho, que definiu regras para os reajustes salariais, dificultando qualquer margem de interpretação judicial sobre o índice inflacionário. Na prática, impôs aos trabalhadores dos mais diversos setores um arrocho que somente seria vencido, em parte, muitos anos depois, pós-democratização.

\section{A lei do "Trabalho Temporário"}

A Lei 6019/74 regulamentou as "relações trilaterais" ou "assimétricas", abrindo as portas para a terceirização e para os questionamentos posteriores que tiveram reflexos em demandas perante a Justiça do Trabalho. A nova legislação permitiu a contratação de trabalhadores temporários por um período de até 180 dias, desde que contratados para realizarem atividades transitórias da contratante.

Quando se lê a exposição de motivos do projeto de lei, conclui-se haver impressionante similaridade com os argumentos expressos nos fundamentos das propostas que, hoje, buscam regulamentar a terceirização, especialmente o PL 030/2015, hoje no Senado Federal. ${ }^{29}$ Tanto na lei de 1974, quanto nas propostas atuais, os argumentos centramse na "modernização" das relações de trabalho, na necessidade de atualizar a CLT para superar sua suposta "rigidez", no incremento da produtividade e na afirmação de que buscam regulamentar uma prática recorrente: a do trabalho temporário, que precisa ser regulamentado e a da terceirização, que veio para ficar e que precisa ser regulamentada. Porém, não há qualquer evidência de que o trabalho temporário e, no caso atual, a terceirização, impactem positivamente a ampliação dos postos de trabalho, a competitividade e, em especial, melhores a vida do trabalhador.

\footnotetext{
${ }^{28} \mathrm{Id}$.

${ }^{29}$ Sobre a Tramitação do PL 030 do Senado Federal consultar: BIAVASCHI, Magda Barros; TEIXEIRA, Marilane Oliveira. O. A terceirização e seu dinâmico processo de regulamentação no Brasil: limites e possibilidades. Revista da ABET, v.14, n.1, jan.-jun. 2015.
} 


\section{A flexibilização da tela de proteção social: a "segunda onda liberal"}

Os anos que se seguiram ao processo de democratização do País, especialmente na década de 1990, foram inundados por uma avalanche liberal. Intensificada a partir do Plano Real, seguiu sua marcha, ainda com contornos distintos e de forma contraditória ${ }^{30}$. Olhandose para a década de 1990, percebem-se medidas como: redução de barreiras ao livre comércio, viabilização do livre fluxo de investimentos, privatizações, desregulamentação dos mercados, incluídos o financeiro e o do trabalho e, ainda, de setores como energia, transporte e telecomunicações, adotadas no pressuposto de que a intervenção do Estado deveria limitar-se às "brechas" do mercado. "Políticas de ajustamento" e "reformas estruturais" voltaram-se, basicamente, à redução do déficit público e à abertura ao setor privado de caminhos que, até então, eram trilhados apenas pelo setor público.

Sob o argumento de que o Estado era ineficaz, tratou-se de desmontá-lo. Nos compromissos assumidos com o Fundo Monetário Internacional, além das reformas liberalizantes e leis complementares, estava o de aceleração das privatizações, incluídos os Bancos, sistemas de geração e de distribuição de energia elétrica, como ênfase à aprovação de normas que permitam a privatização da água e das redes de esgoto, as reformas do Estado: a Administrativa, a da Previdência e a do Poder Judiciário.

Quanto às normas de proteção ao trabalho, a "segunda onda" introduziu medidas que se colocaram, direta ou indiretamente, na contramão dos princípios do Direito do Trabalho, flexibilizando as formas de contratação, a remuneração, a jornada. São exemplos dessas medidas: a que ampliou as possibilidades de contratação temporária e reduziu as exigências que, em 1943, a CLT escreveu como condicionantes de validade dessa forma de contratação, desvinculando-a da natureza dos serviços prestados, o que, na prática, acabou fazendo da exceção a regra; a mesma que, ainda, introduziu o banco de horas; as Medidas Provisórias adotando marco referencial anual para a compensação, culminando com a MP 2.164-41, de 24 de agosto de 2001, que passou a viger por tempo indeterminado; a Emenda Constitucional 28, que modificou o prazo prescricional dos rurais; a lei que introduziu as Comissões de Conciliação Prévia e que, transferindo para a esfera privada a solução dos conflitos do trabalho, definiu como obrigatória a passagem pela Comissão, introduzindo o mecanismo da "eficácia liberatória de direitos" como chancela de renúncia a direitos irrenunciáveis; a que previu a suspensão temporária dos contratos de emprego; a que definiu como indenizatória a natureza da

\footnotetext{
${ }^{30}$ KREIN, José Dari; BIAVASCHI, Magda Barros. Brasil: os movimentos contraditórios da regulação do trabalho dos anos 2000. CDC [online]. 2015, vol.32, n.89, pp. 47-82.
} 
parcela Participação nos Lucros e nos Resultados; a que tratou da natureza do vínculo jurídico entre os sócios das cooperativas, explicitando não existir relação de emprego.

Esse processo culminou com o encaminhamento, pelo Ministro do Trabalho, Francisco Dornelles, do PL 5.438/2001 propondo alterações ao artigo 618 da CLT: a famosa prevalência do negociado sobre o legislado, cujo cimento foi o princípio da autonomia da vontade, no suposto da existência de relações de troca baseadas na igualdade formal dos contratantes. Como pano de fundo, a ideia de que as formas de convivência engendradas pelo mercado preservam a "liberdade" do indivíduo e "harmonizam" os interesses das partes. Com o objetivo declarado de obter crescimento econômico e trazer os trabalhadores para a formalidade, a proposta elevava a negociação coletiva à condição de fonte primeira de direitos. Aprovada na Câmara dos Deputados, foi arquivada no Senado em 2003, como promessa da coligação Lula Presidente. Interessante que, em 2016, essa proposta aparece com uma das estruturantes da "reforma trabalhista" que o governo Temer pretende levar à efeito, segundo, aliás, constou do Projeto Ponte para o Futuro, do PMDB, não chancelado pela ex-Presidente Dilma, o que pode ter sido um dos elementos que contribui para com o processo de um impeachment fundamentado em suposto crime fiscal.

Os ventos liberais continuaram soprando. Ainda que no período de 2006 a 2013 os índices do mercado de trabalho tenham apresentado sensíveis melhoras, com aumento da formalidade e política de valorização do salário mínimo que aumentou a renda dos trabalhadores, alterações legislativas flexibilizantes continuaram investindo contra princípios do Direito do Trabalho, em especial no primeiro governo Lula, ainda que essa investida tenha sido reduzida no segundo período Lula e, mais ainda, no primeiro Dilma. Registra-se que as medidas desse período que ampliaram a tela de proteção social, com destaque à política de valorização do salário mínimo iniciada em 2005, não estão sendo objeto de análise em face do argumento enfrentado no texto.

No primeiro período Lula, houve duas grandes quebras do princípio da intangibilidade com a Lei de Falências e com a Medida Provisória do Micro Crédito, transformada em lei - Lei 10.820/2003, com as alterações da Lei 10.953/2004 -, e que introduziu o empréstimo bancário mediante pagamento consignado em folha. Ou seja, risco zero para o Banco e quebra do princípio da intangibilidade salarial.

Quanto aos créditos na falência, a Lei 11.101/2005, concomitante à Lei Complementar 118, trouxe modificações, ferindo o pressuposto de que os riscos do negócio são do empregador. O artigo 186 do Código Tributário Nacional afirmava que o crédito tributário preferia a qualquer outro, exceto ao trabalhista. A Lei complementar 118 alterou esse quadro, 
acrescentando um inciso ao artigo 186: a lei poderá estabelecer limites e condições para a preferência dos créditos decorrentes da legislação do trabalho. A Lei de Falências quebrou a preferência dos créditos trabalhistas, atingindo, ainda, a sucessão de empregadores, contemplada pela CLT. Limitando o crédito privilegiado e dispondo sobre a recuperação judicial, em que os credores decidem em assembleia sobre a hierarquia dos pagamentos, revogou o art. $449, \S 1^{\circ}$ da CLT: na falência constituirão créditos privilegiados a totalidade dos salários devidos ao empregado e a totalidade das indenizações a que tiver direito. Os princípios que informam essa lei são contrapostos aos do Direito do Trabalho. A Lei de Falências anterior - Decreto-Lei 7.661, de 21 de junho de 1945 - protegia o trabalhador frente ao falido. O princípio da proteção, aliás, informou a construção do Direito Social.

A Reforma da Previdência deu continuidade às reformas liberalizantes levadas a efeito na década de 1990, afetando os direitos dos servidores ativos e inativos ao estabelecer o fim da integralidade e da paridade e ao fixar no teto do regime geral do INSS o limite a ser percebido ao título de proventos de aposentadoria. Além disso, incluiu a cobrança previdenciária para os inativos; dispôs sobre os fundos de pensão, regulamentando o instituto da aposentadoria complementar.

O Programa Nacional de Primeiro Emprego, PNPE, atribuiu incentivos financeiros às empresas que contratam jovens, por meio do Fundo de Amparo ao Trabalhador. Suas características flexibilizadoras consistem em permitir o contrato a prazo determinado, desde que por período mínimo de 12 meses, recomendando a não substituição de trabalhadores, limitando em $20 \%$ do total os contratados pelo PNPE. Apesar de a motivação ser o estímulo à contratação de jovens, a medida flexibiliza por se fundamentar na tese liberal da redução de custos e incentivos fiscais para viabilizar a contratação.

Em março de 2006 foi encaminhada a MP 284 com duas proposições: isenção fiscal ao empregador doméstico que assina a carteira de trabalho e definição de prazo para recolhimentos previdenciários. No Congresso foi apresentada emenda assegurando ao trabalhador doméstico o direito ao FGTS, objeto de veto presidencial relativamente à obrigatoriedade. Por um lado, a medida ampliou direitos; por outro, ofereceu incentivos ao empregador - renúncia fiscal - para cumprir obrigação exigida: assinatura da carteira de trabalho, sem que os domésticos fossem igualdados aos demais trabalhadores em direitos, o que somente veio acontecer mais tarde, no Governo Dilma.

Ainda no primeiro Lula, a regulamentação do trabalho intelectual estimulou a fraude na contratação ao regulamentar as atividades de natureza artística, científica e de comunicação, possibilitando contratação via pessoa jurídica, estimulando a relação de 
emprego disfarçada. Também foi reformulada a lei de incentivos às micro e pequenas empresas, instituindo o "Simples Nacional”, com previsão de Comissões Extrajudiciais para a solução dos conflitos individuais do trabalho e na liberação das empresas dos controles de horário, dificultando a prova das horas extras em caso de litígio.

No segundo Lula, medidas flexibilizadoras, mais escassas, podem ser apontadas: a regulamentação do trabalho em transporte rodoviário de cargas e do trabalho rural por tempo determinado; a primeira, estimulando as relações de emprego disfarçadas, enfraquecendo as garantias dos trabalhadores. Quanto ao trabalho rural temporário, adotada com a justificativa de estimular a formalização das relações de trabalho no campo via contratos por tempo determinado, liberou o empregador de registrar o contrato na carteira de trabalho e de incluir o nome do trabalhador no livro ou ficha de registro de empregados.

De fato, houve avanço na regulação pública do trabalho. Porém, persistiu o movimento que fragilizou a proteção ao trabalho ${ }^{31}$. Já a terceirização avançou nos setores privado e público, com potencial altamente precarizador, e cujo projeto de regulamentação em andamento, hoje no Senado - PLC 30/2015 - amplia as possibilidades de seu uso para quaisquer atividades, mesmo essenciais à tomadora, representando retrocesso em relação à Súmula 331 do TST. E ainda que os dados do mercado de trabalho tenham apresentado melhorias nesse período, a informalidade e a rotatividade se mantiveram elevadas, persistido elementos de flexibilização das relações de trabalho, como se mostra no artigo no que fundamenta este subitem. ${ }^{32}$

\section{CONSIDERAÇÕES FINAIS}

Neste artigo, em que se procedeu a um diálogo entre as flexibilizações das normas de proteção social ao trabalho durante a "primeira onda liberal" e aquelas aprofundadas durante a "segunda onda", desnudou-se a falácia do argumento dos que, defendendo a reforma da CLT, centram suas teses em sua propalada "rigidez" e na necessidade de que seja "modernizada". Ficou evidente que a legislação brasileira, bastante flexível, viu muitos dos princípios que a fundamentam atingidos bruscamente em momentos distintos da história brasileira. O que fica claro é que há uma disputa entre duas formas de compreender a relevância de um patamar civilizatório que a regulamentação social do trabalho possa oferecer: de um lado, setores empresariais, economistas e estudiosos, adeptos a certa corrente de pensamento, destacam a

\footnotetext{
31 KREIN, José Dari; BIAVASCHI, Magda Barros. Brasil: os movimentos contraditórios da regulação do trabalho dos anos 2000. CDC [online]. 2015, vol.32, n.89, pp. 47-82.

${ }^{32} \mathrm{Id}$.
} 
incompatibilidade de sua "rigidez" com os "tempos modernos", defendendo que, para o incremento da produtividade a da competitividade em nível mundial, deve ela ser flexibilizada. De outro, expoentes do pensamento econômico heterodoxo afirmam ser equivocado atribuir à regulamentação do trabalho o motor da competitividade, defendendo que os direitos sociais, conquistados contra as "leis naturais" do capitalismo, não podem sucumbir frente à competição internacional dos mercados. Isso em tempos em que nos quatro cantos do mundo, salvo exceções, os direitos sociais perdem terreno à ação da "força bruta" de um capitalismo "sem peias".

O que também fica evidente é que após 1964 se reduziram as possibilidade de ampliação dos direitos sociais, mesmo que tenhamos vistos certos avanços proporcionados pela Constituição de 1988 a regra geral pode ser descrita como a flexibilização das normas. Os trabalhadores passaram a enfrentar uma serie de propostas legislativas que retiravam, reduziam ou davam outra conotação a legislação existente.

$\mathrm{O}$ artigo dialogou com esses argumentos, partindo do pressuposto de que a legislação trabalhista brasileira é flexível, com alterações pontuais que foram sendo realizadas em resposta às fortes pressões no sentido da desconstrução das conquistas dos trabalhadores. $\mathrm{O}$ que salientou foi que a CLT representou um avanço no sentido de garantir direitos que correspondam a um patamar civilizatório mínimo, colocando diques à ação de um capitalismo em processo de constituição, com positivação de regras que foram incorporando princípios que dão fisionomia ao Direito do Trabalho, entre eles: o da proteção, o da aplicação da norma mais favorável, o da aplicação da regra da condição mais benéfica, o da irrenunciabilidade dos direitos assegurados por normas de ordem pública, o da irredutibilidade salarial, o da primazia da realidade. 


\section{BIBLIOGRAFIA}

BELLUZZO, Luiz Gonzaga. O capital e suas metamorfoses. São Paulo: UNESP, 2013.

BIAVASCHI, Magda Barros. O Direito do Trabalho no Brasil - 1930-1942: a construção do sujeito de direitos trabalhistas. São Paulo: LTr, 2007.

A construção das normas de proteção social ao trabalho e seus fundamentos: uma homenagem à Professora Gabriela Neves Delgado. In: VIANA,

Márcio Túlio: ROCHA, Cláudio Jannotti da (Orgs.). Como aplicar a CLT à luz da Constituição: alternativas para os que militam no foro trabalhista. São Paulo: LTr, 2016, p. 19-27.

- Exposição de Motivos. In: A CLT comentada/Rodrigo Trindade de Souza, Coordenador. São Paulo: LTR, 2015, p. 22.

São Paulo, 1980.

; TEIXEIRA, Marilane Oliveira. O. A terceirização e seu dinâmico processo de regulamentação no Brasil: limites e possibilidades. Revista da ABET, v.14, n.1, jan.-jun. 2015.

CORREA, Larissa Rosa. Os inimigos da pátria: repressão e luta dos trabalhadores do sindicato dos químicos de São Paulo (1964-1979), Revista Brasileira de História. São Paulo, V. 34, nº 67, p.13-37, 2014.

CORRÊA, Larissa Rosa. A rebelião dos índices: política salaria e Justiça do Trabalho na ditadura Civil- Militar (1964-1968). A Justiça do Trabalho e sua história. Edunicamp, Campinas, 2013.

DROPPA, Alisson. Direitos Trabalhistas: Legislação, Justiça do Trabalho e Trabalhadores no Rio Grande do Sul (1958- 1964). Tese de doutorado em História. UNICAMP/IFCH, Campinas, 2015.

FONSECA, Pedro Cezar Dutra. Vargas: o capitalismo em construção - 1906-1954. São Paulo: Brasiliense, 1989.

KREIN, José Dari; BIAVASCHI, Magda Barros. Brasil: os movimentos contraditórios da regulação do trabalho dos anos 2000. CDC [online]. 2015, vol.32, n.89, pp. 47-82.

NEGRO, Antonio Luigi; CORRÊA, Larissa Rosa; FONTES, Paulo. Trabalhadores e Ditadura. Mundos do Trabalho, Florianópolis, v. 6, n. 11, p. 5-8, jan. 2015.

SCHUMPETER, Joseph A. Capitalismo, socialismo e democracia. New York: Harper \& Row, 1975. 